\title{
Wireless and mobile technologies to enhance teaching and learning
}

\author{
T.C. Liu, H.Y. Wang, J.K. Liang, T.W. Chan, H.W. Ko \& J.C. Yang \\ National Central University, Taiwan.
}

\begin{abstract}
This research aims to build a Wireless Technology Enhanced Classroom (WiTEC) that supports everyday activities unobtrusively and seamlessly in classroom contexts. This paper describes the integration of wireless LAN, wireless mobile learning devices, an electronic whiteboard, an interactive classroom server, and a resource and class management server to build the WiTEC. This contains a number of features that can support class members in various types of teaching and learning activities. Project-based learning is taken as a scenario to elaborate how teachers and students can engage in teaching and learning via WiTEC. Finally, a number of suggestions are discussed for further study.
\end{abstract}

Keywords: Wireless; Mobile; Ubiquitous computing; Project-based learning; Interactive; Primary, IT-use

\section{Introduction}

The campus environment, especially in the classroom, is an appropriate location to put ubiquitous computing into practice (Weiser, 1998). Ubiquitous computing means that the computing system is 'calm' and is a part of everyday environment, and user's interaction with the computing system is available wherever the user needs it (Weiser, 1991; Weiser et al. 1999). Some recent studies have adopted ubiquitous computing technology to build a technology-supported classroom environment that is free from obstacles caused by using technology. Among them, the eClass (Abowd, 1999) and the Computer-integrated classroom (Hoppe et al., 2000; Tewissen et al., 2001) are learning environments that have been applied in real classroom practice. Their computing power is embedded in the frequently used facilities in classrooms, such as whiteboards. The operation of these facilities is not strange to teachers and students. The human and computer interact unconsciously and hence teachers and students benefit from this process. The eClass project focused on undergraduate and graduate students' presentation-style lectures to construct an instrumented environment. The major function of eClass is to capture and integrate automatically various information of a teacher's lecture, including lecture notes, materials, voice, and images, to form available multimedia courseware, so as to facilitate users' access and review on the Internet after class (Abowd, 1999). In addition, a Computerintegrated Classroom features a number of special but easily used hardware, such as an interactive whiteboard and handwriting tablets embedded in students' desks in a

Accepted 15 April 2003

Correspondence: Tzu-Chien Liu, Graduate Institute of Learning \& Instruction, National Central University, No. 300, Jung-da Rd., Jung-li, Taoyuan, Taiwan 320, R.O.C. Email: 1tc@cc.ncu.edu.tw 
networked environment with groupware functions (Hoppe et al., 2000; Tewissen et al., 2001). In the long term and common practice, even young learners could flexibly carry out collaborative learning in this classroom environment (Tewissen et al., 2001). This research result is an encouragement to researchers who want to actualise the notion of ubiquitous computing in living classrooms.

In recent years, the development of mobile devices, wireless communication and network technologies have been drastically advanced. Their integration can expand technologies as a part of campus environment for teachers and students to use (Weiser, 1998). Mobile devices enable the teacher and students to utilize computing power anytime and anywhere, while the Internet and wireless techologies enable mobile devices to interconnect with other computing devices seamlessly. Recent empirical studies have suggested the advantages of using wireless technologies and mobile devices in learning environments, including enhancing availability and accessibility of information networks (Gay et al., 2001; Goldman \& Kaufman, 2001), engaging students in learning-related activities in diverse physical locations, supporting group work on projects, and enhancing communication and collaborative learning in the classroom (Gay et al., 2001).

In light of the notion of ubiquitous computing (Weiser, 1991; 1998; Weiser et al., 1999), this study integrates mobile devices, wireless communication, and network technologies to construct a wireless technology enhanced classroom (WiTEC), which includes the following features:

- reducing the time for tedious work,

- engaging students in learning activities,

- empowering the teacher to monitor students' learning statuses,

- facilitating group collaborative learning,

- recording teaching and learning processes as portfolios, and

- implementing technology-supported activities smoothly.

These features will be elaborated in later sections. Furthermore, this study portrays a scenario of project-based learning. This scenario illustrates how the teacher and students use relevant functions in the WiTEC to effectively implement the projectbased learning. Finally, the results of this study are summarised in the conclusion and issues are suggested for further study.

\section{Environment design of WiTEC}

Early work focused on the development of a highly interactive classroom, where wireless handheld devices were introduced into the living classroom (Huang et al., 2001; Wang et al., 2001). Each student in the highly interactive classroom has a handheld infrared remote controller for participating in learning activities, such as individual- and group-based competition and formative evaluations. The infrared remote controller, the lowest-cost entry-level user device, allows students to interact with the teacher and other students through the support of the classroom computer (Wang et al., 2001). Previous research demonstrated that the highly interactive classroom not only increases the utility rate of class computers but also enhances students' attention and interests of learning (Wang et al., 2001). However, the remote controller has some limitations, for example, students can only have fixed options on the remote controller rather than input their response by typing, and the remote controller can only support students to respond to their teacher rather than support the teacher to give feedback to students or exchange messages between 
students. These limitations impose restrictions on some of the learning activities (Ko \& Liu, 2001). These limitations were alleviated by establishing the WiTEC.

The WiTEC, which is an improved version of the highly interactive classroom, enhances wireless communication by replacing infrared beaming with $802.11 \mathrm{~b}$ wireless access points and replacing the infrared remote controller with the mobile learning device as students' personal tool. Also, the WiTEC is equipped with an electronic whiteboard for teachers to teach as well as control and coordinate learning activities. The environment design of the WiTEC is shown in Fig. 1.

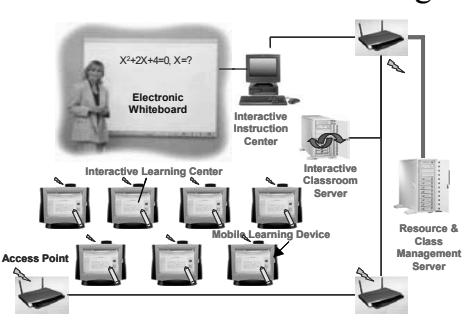

Fig. 1. Environment design of WiTEC. In the WiTEC, a teacher can implement teaching activities supported by an ewhiteboard, and each student can use a mobile learning device to learn individually or interact with other classmates and teachers. The e-whiteboard is connected to a classroom computer so that the teacher can teach as usual but with computing power. Students can read digitised contents, practice assignments, and participate in learning activities through mobile learning devices. Two servers, an interactive classroom server (ICS) and a resource and class management server (RCMS), are used to assist teaching and learning activities in the WiTEC. The ICS is a coordinator that coordinates the exchange of messages among different devices. The RCMS is a resource centre that manages resources and keeps records of individual student's learning portfolio. The WiTEC was established by March 2002 and is now being used in three sixth-grade classes with 12 to 13-year old students in Nan-Hu Elementary School in Taipei.

\section{Interactive instruction centre and interactive learning centre}

In the WiTEC, there are two clients for teachers and students respectively. The interactive instruction centre (IIC) supports the teacher with various functions to guide and monitor students' participation and to implement various teaching activities. Moreover, the interactive learning centre (ILC) is the learning portal installed on the mobile device, used by learners to participate in learning activities.

\section{Interactive instruction centre for teachers}

Although educators encourage and accept student autonomy and initiative (i.e. Brooks \& Brooks, 1993), it does not mean that the teacher can let students learn anything arbitarily. In fact, the role of teachers in classrooms has shifted to be a mediator, supporter, facilitator or guide of learning. The teacher must assist students to engage in learning activities, help them to make meaningful connections to prior and new knowledge (Copley, 1992) and monitor their learning process. Moreover, the teacher should observe whether students deviate from the subject matter or develop misconceptions, and decide when to intervene in students' learning process (Brown \& Campione, 1994). Therefore, teachers' roles may become more important and more challenging (Applefield et al., 2000).

The major purpose of the IIC is to assist teachers to play the above-mentioned roles during everyday classes. IIC is installed on the classroom computer that is connected to an e-whiteboard, so that teachers can operate the IIC through ewhiteboard. The teacher presents pre-authored contents, such as presentation slides, 


\section{T-C. Liu et al.}

web pages, videos, and online quizzes, by simply clicking on a file name listed on the panel. The selected frames can be broadcast to all students, multicast to group members or uni-cast to a single student in the classroom under the ICS coordination. Frames, URLs, programs, and recorded information are delivered not only from the teacher to students, but also from students to the teacher. These functions help teachers to monitor and facilitate students' learning. During teaching, all of the notes and marks made by the teacher on the e-whiteboard can be recorded in the RCMS and could be replayed anytime.

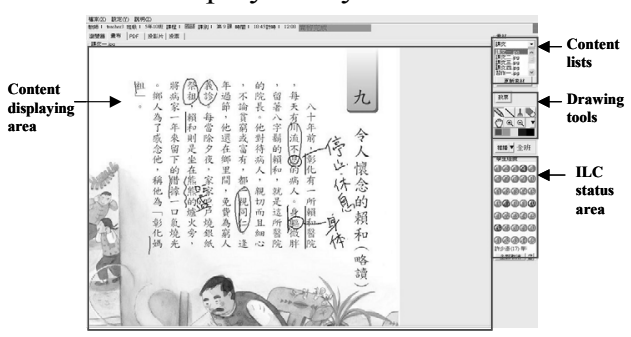

Fig. 2. Functions of the IIC

The learning status area on the right lower corner of the IIC panel, as shown in Fig. 2, provides teachers with information about students' current status, and enables them to determine whether to modify the teaching or to intervene in students' learning. Different colour signals in the area display students' status: green for on-line, yellow for lagging connection, black for disconnection and red for requesting help. As the number of yellow signals on the panel increases, the teacher should slow down the teaching. When red signals are shown, the teacher can provide assistance immediately. The learning status area is also an interface by which the teacher can choose a specific number-signal to display the corresponding student's working frame on the IIC panel. This design is feasible in both collaborative learning and individualised learning. As the designated student's frame displayed on the IIC panel, the teacher can note directly on the ewhiteboard and all the notes can be stored in the RCMS together with the student's learning records so that both the teacher and students could re-trace and review the learning and teaching process.

\section{Interactive learning centre for students}

Meaningful learning takes places through learners' interactions with peers and their own interactions within content-rich contexts (Greeno, 1997). Therefore, constructing a resource-rich and interaction-rich learning environment is essential to facilitate students' meaningful learning. Resources in ordinary classrooms are heavily restricted (Roschelle et al., 2000) which discourages learners to inquire, discover, analyse and solve problems. In ordinary computer classrooms, although the Internet brings a lot of resources, the fixed PCs and network infrastructure often hinder students from flexibly and fluently shifting between computer-embedded learning and other learning activities (Morrison et al. 1999).

Mobile learning devices can solve this dilemma in traditional and computer classrooms and allow students to participate in both physical and virtual learning activities. The mobile learning device used in this study is a Windows CE OS webpad with 10.4-inches TFT-LCD touch panel and built-in $802.11 \mathrm{~b}$ wireless LAN card. As a handwriting wireless communication device, the mobile learning device is the main device students used to participate in the learning activities in the WiTEC.

ILC is installed on the mobile learning device. There are six components in ILC to support learners to share and exchange materials, interact with each other, and record their performance. These components include the shell, web browser, 
freestyle drawing tools, interactive assessment tools, broadcast viewer, and task controller. Figure 3 shows the system architecture of ILC. The shell is the interface between users and ILC. The web browser is embedded as a content displaying component that displays multimedia and web pages.

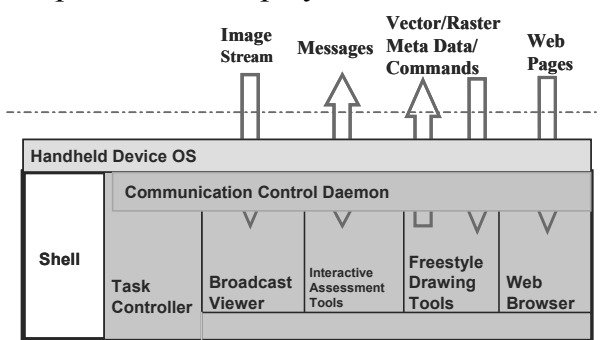

Fig. 3. System architecture of the ILC

Freestyle drawing tools support vector and raster functions for students to do their exercises and take notes. All the metadata generated in the ILC can be recorded and sent to the RCMS through ICS. Interactive assessment tools are the major component that enable students to participate in both synchronous and asynchronous evaluation activities in the WiTEC. The

broadcast viewer coordinates with IIC to synchronously display teaching frame, URLs, and application programs broadcast from IIC. The IIC can also catch an ILC frame and broadcast it to other students' ILCs.

To support interactive activities in the classroom, a built-in communication control daemon keeps track of all communication messages that students make on the

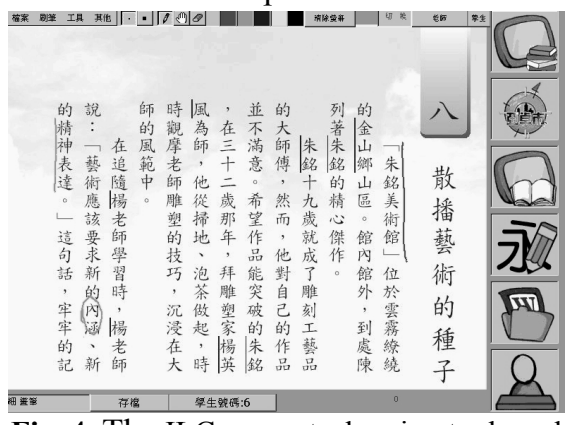

Fig. 4. The ILC supports drawing tools and group interaction tools mobile learning device by using ILC functions. Figure 4 shows that the ILC received a frame sent from IIC and the student uses the freestyle drawing tool to make his/her own notes. All the recorded messages are constantly transmitted to the ICS and stored in the RCMS as an individual portfolio. The communication control daemon also receives messages, image stream, commands, and teaching materials sent from IIC and dispatches them to the relevant components of the

ILC for further processing. As the IIC delivers a command, it forces the ILC to display a designated frame or file content synchronously, and the task controller then switches the system to the corresponding component.

\section{WiTEC servers}

The servers of the WiTEC, including RCMS and ICS, handle resources and interactivities. RCMS reserves and manage teaching and learning resources, activity content, students' learning portfolios, and teacher's teaching records. ICS keeps track of individual operating processes as well as coordinates teacher-student and peer interactions.

\section{Resource and class management server}

RCMS is the content and activity manager in the WiTEC. The server provides teachers with essential tools, such as quiz authoring and teaching materials sequencing for course contents preparation. Through RCMS, all of the teaching materials, including pictures, videos, audios, homepages, and presentation files, are arranged before teaching and used in class. After class, through the Internet to log in 
RCMS, the students can undertake the assigned exercises or review the in-class teachers' notes written on the e-whiteboard.

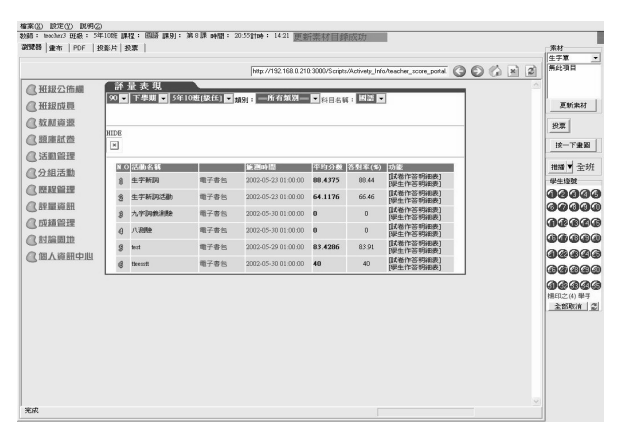

Fig. 5. Learning portfolios stored on the

In addition to providing the contents and activities management, RCMS is the class member manager that supports the teacher to create students' profiles, including names, class IDs, and email addresses, and stores students' learning portfolios generated through the ILC. Furthermore, RCMS stores each student's learning records, as shown in Fig. 5. All students can $\log$ into the server and review what they had done in class. RCMS also enables teachers to assign students to different groups based on the need of collaborative learning, and facilitates them in using IIC to deliver different learning materials to different groups and to administer evaluations based on the performance of the whole group.

\section{Interactive classroom server}

To cope with enormous amount of interaction and effectively integrate the work of IIC, ILC, and RCMS, ICS has been developed to coordinate activities and content

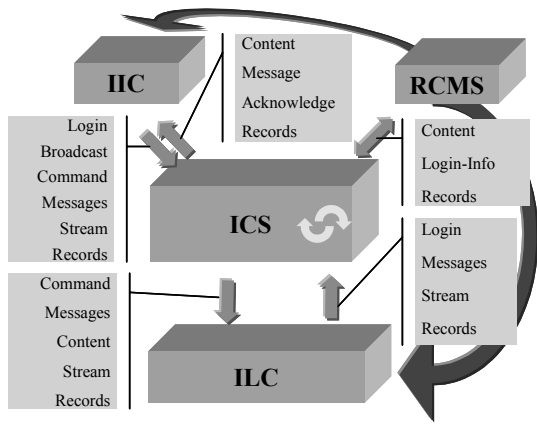

Fig. 6. The ICS is the coordinator of activities and contents during teaching. Figure 6 illustrates the role of the ICS in the WiTEC. The ILC automatically logs into the ICS once a mobile learning device is carried into the classroom and turned on by a student. Successive operations on the ILC will be monitored by ICS. All the operations, such as drawing and clicking on the mobile learning device, are transformed to messages and commands. ICS parses these messages and commands to execute corresponding functions. For instance, when a student requests a specific quiz on

ILC, this command will be sent to ICS. As ICS receives the command, it then transmits the ILC's ID and quiz name to RCMS. The requested quiz is then passed along to the ILC. After the quiz is finished, responses for each item are automatically recorded in the student's portfolio.

\section{The features of WiTEC}

In this section various features of the WiTEC supporting in-class teaching and learning are discussed from educational perspectives.

- Reducing the time for tedious work. The activities in classrooms include some frequent and tedious tasks. For example, a teacher gives students worksheets and test papers and then collects them after students finish their work, or ask students to rewrite and demonstrate their completed assignment on a whiteboard. Such a procedure takes much time and often interrupts the ongoing teaching activity. In 
the WiTEC, the teacher can select ready-prepared materials or worksheets through the e-whiteboard, and broadcast them to mobile learning device(s) of all students, a group of students, or an individual student. On the e-whiteboard, the teacher can also click a specific students' number to present his/her working frame, mark and correct any mistakes directly, and then send the revised version back. These designs enable numerous tedious tasks to be completed at once, and hence allowing teachers to have more time to guide students' learning, and keep teaching activities running smoothly.

- Engaging students in learning activities. Because of the limited resources in ordinary classrooms, students often merely accept the ready-prepared materials during learning activities. In the WiTEC, each student can use the mobile learning device to explore, collect, read, and organise online course-related resources, and then complete the assignment collaboratively on RCMS's mutual workspace. Depending on their needs, the students can take their own mobile learning device around the classroom to participate in different learning activities. Additionally, the teacher in the WiTEC can present quizzes on the ewhiteboard for each student to answer through his/her mobile learning device. After all students finish the quiz, the teacher can use IIC to either juxtapose students' answers if the quiz requires short answer, or summarise all students' answers in a bar chart if the quiz is multiple-choice. With this information, the teacher can understand the distribution of all students' opinions, and can accordingly guide the students to engage in deep discussion. Because every student has a role in the aggregate representation, they may take a more active role in subsequent discussions (Roschelle \& Pea, 2002). These functions can engage students in learning activities.

- Facilitating group collaborative learning. To implement collaborative learning activities in classrooms, teachers often confront two problems. First, students mostly exchange ideas verbally and thus the process of interaction could not be recorded. This problem makes these activities more goal/result-oriented rather than process-oriented. Second, owing to the competing pressure between groups, the high ability students in a group tend to dominate the whole learning activity, which in turn deprives the lower-ability students of their learning opportunities in group activities (Aronson \& Patnoe, 1995). Group members in the WiTEC are not only able to discuss with each other face-to-face, but also able to exchange individual materials through the mobile learning device. They take notes on the exchanged materials shown on the device and thus the process of interaction could be recorded. Additionally, all the group members can finish the assignment collaboratively on the mutual workspace. For example, when coconstructing group presentation slides, each group member can use his/her mobile learning device to collect and organise data for the assigned part of the slides and then reserve them in the mutual workspace. During this process, each member in the group can also retrieve others' work on the mutual workspace for reference at any time. After every group member's assigned work is finished, all slides can be collected and constructed as a whole, and then revised if necessary. The completed group reports will automatically reveal the original author's name of each part. This functionality motivates each group member not only to engage in the group work, but also to actively interact with others.

- Empowering the teacher to monitor students' learning statuses. Generally, a 
wireless learning environment can facilitate students' individual or collaborative learning and expand their activity space, but it might be difficult for teachers to monitor each student's current learning status. To overcome such difficulties, the WiTEC provides some solutions. On IIC, each number-signal corresponds to one student, and different colours of signals stand for different status in using a mobile learning device. A teacher can determine how to implement the subsequent activities depending on the colours of number-signal. For example, if a student's signal colour is black when a teacher interprets materials on the IIC, this means that this student's device is disconnected with IIC. The teacher can thus check whether this student is using the device to do irrelevant works (i.e. random browsing on the Internet). Moreover, if a student's signal colour is red during learning, this indicates that the student requests the teacher's help. These features allow teachers to understand all students' learning status in the classroom for further teaching decisions.

- Recording teaching and learning processes as portfolios. Before class, teachers need to systematically construct teaching materials in RCMS for themselves and learners to use during learning and teaching. Meanwhile, through the mobile learning device ILC records learners' processes as learning portfolios in the individual or group archive in RCMS. These functions facilitate the establishment of teaching records and learning portfolios and then promote teachers' reflection on teaching as well as learners' portfolio assessment.

- Implementing technology-supported activities smoothly. To allow teachers and students benefit from technology easily, there are two features of WiTEC's design: the user-friendly interface and the ICS. Specifically, either an ewhiteboard or a mobile learning device can allow users to input data by handwriting. Moreover, ICS can deal with enormous amounts of interaction and effectively coordinate the work of all systems in the WiTEC. Therefore, all learning and teaching activities can be conducted smoothly.

In summary, the teacher and students in the WiTEC environment can use technology in unobtrusively and seamlessly ways to reduce the time spent in tedious tasks, engage in various types of teaching and learning activities, and then record their process as portfolios. The next section portrays how the features of WiTEC can effectively help the teacher and students carry out project-based learning that is difficult to be implemented in ordinary classrooms.

\section{Implementing project-based learning in the WiTEC}

Project-based learning is a learning model that organises learning around one or several projects, which involve students in designing, investigating, problemsolving, or decision-making (Katz \& Chard, 2000; Thomas, 2000). Previous research has reported several strengths of enacting project-based learning in classrooms, such as enhancing students' capability of inquiry and sophisticated thinking (Krajcik et al., 1998), increasing students' attitude toward learning (Tretten \& Zachariou, 1997) and promoting students' understanding of the specific skills and strategies introduced in the project (Barron et al., 1998). However, some limitations of implementation have been observed. Students have difficulties in generating meaningful and insightful questions as well as developing a logical argument to support claims (Thomas, 2000). Besides, it is difficult for the teacher to control the flow of information students may access, to scaffold students' activities to support 


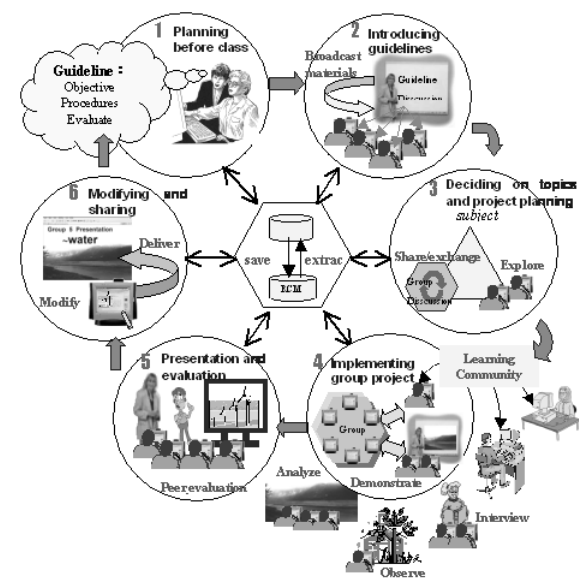

Fig. 7. Implementing project-based learning in the WiTEC

learning and to integrate technology into classroom (Marx et al., 1994). A scenario of a sixth-grade class, shown in Fig. 7 illustrates the procedures of project-based learning with WiTEC's features mentioned above.

The shortage of water is a global issue and Taiwan is facing this problem due to insufficient rainfall. A sixth-grade teacher decides to choose the 'Exploration of water resources' as a topic. She encourages students to collaboratively plan how to implement the project and study relevant topics in their group. Moreover, she expects that through project-based learning students not only construct knowledge associated with water resources and develop the ability of problem solving, but also cultivate the concept and habit of saving water resources. The teacher guides all students through the following phases:

- Preparing before the class. The teacher has drawn up some guidelines about learning tasks, including learning objectives, assessment methods and their criteria, and the procedures. Furthermore, the teacher collects online information for students to read and to explore. The guidelines and related links of these online resources are stored in the RCMS for further sorting and managing.

- Introducing guidelines. In this phase, the teacher introduces and discusses the learning activity with the students. In the WiTEC, the teacher uses an ewhiteboard to illustrate the ready-prepared guidelines of learning tasks to the whole class. If necessary, she can immediately revise the guidelines on the ewhiteboard according to the outcomes of discussions and then broadcast the revised guidelines and prepared learning resources to each student's mobile learning device for use in the next phase.

- Designing the topic and planning projects. Each student uses their mobile learning device to participate in the designated group. Group members sometimes use mobile learning devices to browse the learning resources provided by the teacher or explore more learning resources on the Internet. By finding useful information, they can share it with other group members via the mutual workspace. They sometimes discuss the collected information face-toface and record the discussion results by using their mobile learning device. They also review the guidelines of learning tasks that the teacher broadcasts to each device. Through the reciprocal process of exploring, collecting, sharing, discussing and recording, members in each group eventually develop a project topic (i.e. the methods of saving water, the prevention of water pollution, etc.) and schedule plans that they want to carry out, and assigned tasks for each group member to work on. The teacher then asks the representative of each group to present, share and discuss their own project topic, and scheduled plan on the ewhiteboard with others. The teacher and other groups' members provide comments for modification.

- Implementing group project. In the following weeks, members in each group 
carry out the project based on the revised plan and individually designated tasks. Students may use their own mobile learning device to read provided materials, or to collect and manage the online resources; also, they may use email or participate in various online communities to request project-related materials. Depending on the needs, after class they may carry their mobile learning device to participate in the relevant activities (i.e. interviews) and record the collected data. In this phase, group members constantly discuss with each other and record the gathered data or unfinished work in the mutual workspace for other group members' reference. If the group members encounter problems, they may use their mobile learning device to seek the teacher's or other group member's help. During this phase, the teacher can review the ongoing learning portfolio of each group to understand what they are doing and intervene in their discussion if necessary. If the teacher finds one group is doing something that would benefit the other groups, she can immediately retrieve the sample on the e-whiteboard and demonstrate it to the whole class. At the end of this phase, members in each group record their finished work in the mutual workspace and, through the process of arranging, integrating and revising, group members accomplish their final report.

- Presentation and evaluation. The representative of each group retrieves the group's finished project from RCMS and demonstrates it on the e-whiteboard to report to and discuss with the whole class. The students in other groups not only orally question and give suggestions to the presentation, but also provide opinions with the ready-prepared peer-evaluation checklist on the mobile device and then record the completed checklist in RCMS for teachers to grade and for other groups to refer.

- Revising, sharing, and grading. Each group revises their own project based on the other students' suggestions. After revision, these groups record the completed project as a specific 'Water Resources' file in RCMS for further reference. Besides, the teacher can retrieve the projects and each student's learning portfolio from RCMS, and then grade them on the IIC.

\section{Conclusion}

This study integrated mobile learning devices, wireless communication and network technologies to build the WiTEC. In contrast with traditional classrooms, the WiTEC enables the teacher and students to concentrate on teaching and learning itself rather than spend too much time and effort on tedious tasks. It helps the teacher to monitor, easily, each student's learning status for further guidance, engages students in learning activities, facilitates students' group collaboration and empowers the teacher and students to apply technologies to a variety of traditional and innovative learning and teaching activtities seamlessly.

The WiTEC has been established and experimented with in three sixth-grade classes of Nan-Hu Elementary School in Taipei, but a number of issues remain to be further explored. First, introducing mobile learning devices into teaching and learning activities in classrooms may change current classroom phenomena, such as the types of classroom interaction (Liu et al., 2002), social relations between class members and the nature of teaching materials and assignments. Thus, further investigation is needed to evaluate how these changes affect students' learning process. Second, although the WiTEC can generally support various types of 
teaching and learning activities, Gay et al. (2001) noted that 'not every teaching activity or learning community can or should successfully integrate mobile computing applications' (p. 273). Different structures of classes, learning content, pedagogical models and curricular philosophies all influence how wireless technologies may be used most effectively. Therefore, in addition to the projectbased leaning that has been applied in this experiment, it is necessary to consider if other innovative learning approaches are appropriate for the WiTEC. Finally, whether or not the WiTEC can achieve its anticipated capabilities and facilitate students' learning effectively depends on how the teacher and students use it. Therefore, it is important to guide class members appropriately using various functions of the device and to immerse these technologies with everyday teaching and learning activities (Ko \& Liu, 2001). Compared with conventional classrooms and computer classrooms, the WiTEC is still viewed as an innovative technology by most teachers and students. Therefore, developing appropriate guiding models for effective implementation is the key for the WiTEC to progress from the research stage to practical use in the future.

\section{Acknowledgements}

The authors would like to thank the two referees for valuable suggestions, and the Bureau of Educational Administration of Taipei City Government and the Ministry of Education of the Republic of China for the financial support of this research under Contract no. 89-H-FA07-1-4.

\section{References}

Abowd, G.D. (1999) Classroom 2000: An experiment with the instrumentation of a living educational environment. IBM Systems Journal, 38, 4, 508-530.

Applefield, J.M., Huber, R. \& Mahnaz, M. (2000) Constructivism in theory and practice: toward a better understanding. High School Journal, 84, 2, 35-59.

Aronson, E. \& Patnoe, S. (1995) The Jigsaw classroom. Building Cooperation in the Classroom. Addison-Wesley, Reading, MA.

Barron, B., Schwartz, D.L., Vye, N.J., Moore, A., Petrosino, A., Zech, L. \& Bransford, J.D. (1998) Doing with understanding: Lessons from research on problem- and project-based learning. Journal of the Learning Sciences, 7, 271-311.

Brooks, J.G. \& Brooks, M.G. (1993) In search of understanding: The case for constructivist classrooms. Association for Supervision and Curriculum Development, Alexandria, VA.

Brown, A.L. \& Campione, J.C. (1994) Guided discovery in a community of learners. In Classroom Lessons: Integrating Cognitive Theory and Classroom Practice (ed. K. McGilly) pp. 229-272. MIT Press/Bradford Books, Cambridge, MA.

Copley, J. (1992) The integration of teacher education and technology: A constructivist model. In Technology and Teacher Education Annual - 1992 (eds. D. Carey, R. Carey, D. Willis \& J. Willis) pp. 617-622. Association for the Advancement of Computing in Education, Charlottesville, VA.

Gay, G., Stefanone, M., Grace-Martin, M. \& Hembrooke, H. (2001) The effects of wireless computing in collaborative learning environments. International Journal of HumanComputer Interaction, 13, 2, 257-276.

Goldman, P. \& Kaufman, B. (2001) How to push an elephant through a straw: Using wireless technology in a web-enhanced skills program. International Review of Law Computers and Technology, 15, 3, 281-299.

Greeno. J.G. (1997) On claims that answer the wrong questions. Educational Researcher, 26, $1,5-17$.

(C) 2003 Blackwell Publishing Ltd, Journal of Computer Assisted Learning, 19, 371-382 
Hoppe, U., Lingnau, A., Machado, I., Paiva, A., Prada, R. \& Tewissen, F. (2000) Supporting Collaborative Activities in Computer Integrated Classrooms - the NIMIS Approach. In Proceeding of CRIWG 2000 (eds. P. Antunes \& C. Salgado), pp. 94-101. IEEE Computer Society Publication, Los Alamitos, CA.

Huang, C.W., Liang, J.K. \& Wang, H.Y. (2001) Educlick: A Computer-supported Formative Evaluation System with Wireless Devices in Ordinary Classroom In Proceedings of ICCE 2001 (eds. C.H. Lee, S. Lajoie, R. Mizoguchi, Y.D. Yoo \& B. Boulay), pp. 1462-1469. Incheon National University of Education Publications, Seoul, Korea.

Katz, L.G. \& Chard, S.C. (2000) Engaging Children's Minds: the Project Approach. Ablex Publishing Corporation, Stamford, Connecticut

Ko, H.W. \& Liu, T.C. (2001) When technology comes into classrooms. In Proceedings of GCCCE/ICCAI 2001 (eds. G. Chen \& J. Yang), pp. 17-20. NCU Publications, Chung-Li, Taiwan.

Krajcik, J.S., Blumenfeld, P.C., Marx, R.W., Bass, K.M. \& Fredricks, J. (1998) Inquiry in project-based science classrooms: Initial attempts by middle school students. Journal of the Learning Sciences, 7, 313-350.

Liu, T.C., Wang, H.Y., Liang, J.K., Chan, T.W. \& Yang, J.C. (2002) Applying wireless technologies to build a highly interactive learning environment. In Proceedings of IEEE International Workshop on Mobile and Wireless Technologies in Education (WMTE 2002) (eds. M. Milrad, U. Hoppe \& Kinshuk) pp. 63-70. IEEE Publications, Los Alamitos, CA.

Marx, R.W., Blumenfeld, P.C., Krajcik, J.S., Blunk, M., Crawford, B., Kelly, B. \& Meyer, K.M. (1994) Enacting project-based science: Experiences of four middle grade teachers. Elementary School Journal, 94, 5, 517-538.

Morrison, G.R., Lowther, D.L. \& DeMeulle. (1999) Integrating Computer Technology Into the Classroom. Prentice Hall, Upper Saddle River, NJ.

Roschelle, J.M. \& Pea, R.D. (2002) A walk on the WILD side: How wireless handhelds may change computer-supported collaborative learning. International Journal of Cognition and Technology, 1, 1, 145-168.

Roschelle, J.M., Pea, R.D., Hoadley, C.M., Gordin, D.N. \& Means, B.M. (2000) Changing How and what children learn in school with computer-based technologies. Future of Children and Computer Technology, 10, 2, 76-101.

Tewissen, F., Lingnau, A., Hoppe, U., Mannhaupt, G. \& Nischk, D. (2001) Collaborative Writing in a computer-integrated classroom for early learning. In Proceedings of EuroCSCL 2001 (eds P. Dillenbourg, A. Eurelings \& K. Hakkarainen), pp. 593-600. Lawrence Erlbaum Associates, NJ.

Thomas, J.W. (2000) A review of research on project-based learning. Autodesk Foundation, San Rafael, CA. <http://www.k12reform.org/foundation/pbl/research/summary.pdf>

Tretten, R. \& Zachariou, P. (1997) Learning about project-based learning: Assessment of project-based learning in tinkertech schools. The Autodesk Foundation, San Rafael, CA.

Wang, H.Y., Liang, J.K., Liu, T.Z., Ko, H.W. \& Chan, T.W. (2001) The highly interactive learning environment design: Integrating and applying the wireless testing system and web-based instruction management system. In Proceedings of GCCCE/ICCAI 2001 (eds. G. Chen \& J. Yang), pp. 1016-1023. NCU Publications, Chung-Li, Taiwan.

Weiser, M. (1991) Some computer science issues in ubiquitous computing. Communications of the $A C M, 36,7,75-84$.

Weiser, M. (1998) The future of ubiquitous computing on campus. Communications of the $A C M, 41,1,42-43$.

Weiser, M., Gold, R. \& Brown, J.S. (1999) The origins of ubiquitous computing research at PARC in the late 1980s. IBM Systems Journal, 38, 4, 693-696. 